\title{
Pranayama: Potential Tools to Enhance Occupational Performance
}

\author{
Venthan J MAILOO ${ }^{1}$, BSc (Hons) MCSP CertMgmt \\ 13rd year occupational therapy student, Osterley Campus, Brunel University, \\ Borough Road, Isleworth, Middlesex TW7 5DU, England UK
}

\begin{abstract}
It has recently been suggested that yogic philosophy provides a model for occupational therapy and that meditation and pranayama (yogic breathing exercises) can facilitate occupational performance. This literature review was undertaken to determine whether there is any evidence to support the use of pranayama to facilitate occupational performance. A literature search using AMED, BNI, CINAHL, HMIC, Medline and Old Medline for the term 'pranayama', limited to English language human research uncovered seven articles clinically applicable to occupational performance. The evidence suggests pranayama can influence, arousal, metabolism and exercise tolerance. Slow alternate nostril breathing should be considered when anxiety impairs occupational performance, and right nostril breathing should be considered for obesity, lethargy, and symptoms of hypothyroidism or similar metabolic disorders that inhibit function. Further research is required for evidence-based application of other pranayama techniques.
\end{abstract}

Key words: exercise, breathing, yoga, pranayama, evidence-based practice

(Asian J Occup Ther 5: 1-10, 2006)

\section{Introduction}

Pranayama are breathing exercises traditionally used in yoga; an Asian system of lifestyle regulation (Mailoo, 2005). Yoga first developed in India thousands of years ago and has branched into four different paths. These are termed Karma, Jnana, Bhakti and Raja (Sivananda Yoga Vedenta Centre, 1999). The traditional purpose of all of these paths was spiritual

Received: February 8, 2006 Accepted: April 4, 2006 Corresponding to: Venthan J Mailoo, 3rd year occupational therapy student, Osterley Campus, Brunel University, Borough Road, Isleworth, Middlesex TW7 5DU, England UK

phone: 44-781-125-1624 fax: 44-20-8959-3376

e-mail: servantofvishnu@gmail.com advancement. Karma yoga is a process of selfless action to avoid incurring sin. Jnana yoga is a philosophical path to spiritual evolution based upon discrimination and dispassion. Bhakti yoga consists of devotional service to God, and can therefore be considered a religious form of yoga. Raja yoga is considered the scientific path because it based on psychology and physiology (Sivananda Yoga Vedenta Centre, 1999).

Bhakti is considered by some to be the branch of yoga most suited to spiritual advancement in modern times (Swami Prabhupada, 1982). Raja yoga however is the best known branch in the West, and is practiced worldwide for its health benefits. Raja yoga has eight steps. These are abstention (from harming others), observance (of self-discipline), steady body postures, pranayama 
Table 1. Pranayama Methods (Sivananda Yoga Vedenta Centre, 1999, Khlasa, 2005)

\begin{tabular}{|c|c|c|c|}
\hline Description & Name & Method & Possible clinical applications \\
\hline $\begin{array}{l}\text { Full yogic } \\
\text { breathing }\end{array}$ & & $\begin{array}{l}\text { 1. On inhalation, expand the abdomen } \\
\text { first, then the ribcage, then the upper } \\
\text { portion of the lungs. } \rightarrow 2 \text {. Breathe out fully } \\
\text { allowing the abdomen to cave in. }\end{array}$ & $\begin{array}{l}\text { Currently used by physiotherapists } \\
\text { to prevent atelectasis. }\end{array}$ \\
\hline $\begin{array}{l}\text { Right nostril } \\
\text { breathing }\end{array}$ & $\begin{array}{l}\text { Surya anuloma } \\
\text { viloma }\end{array}$ & $\begin{array}{l}\text { Close the left nostril and breathe through } \\
\text { the right. }\end{array}$ & $\begin{array}{l}\text { Sympathetic nervous system and } \\
\text { metabolic stimulation. Treatment } \\
\text { of lethargy and obesity. }\end{array}$ \\
\hline $\begin{array}{l}\text { Left nostril } \\
\text { breathing }\end{array}$ & $\begin{array}{l}\text { Chandra anuloma } \\
\text { viloma }\end{array}$ & $\begin{array}{l}\text { Close the right nostril and breathe through } \\
\text { the left. }\end{array}$ & Anxiety management \\
\hline $\begin{array}{l}\text { Alternate nostril } \\
\text { breathing }\end{array}$ & Nadi Shodhana & $\begin{array}{l}\text { 1. Inhale through the right nostril, } \rightarrow \\
2 . \text { Hold breath, } \rightarrow 3 \text {. Exhale through the } \\
\text { left, } \rightarrow 4 \text {. Hold breath, } \rightarrow 5 \text {. Inhale through } \\
\text { he left, } \rightarrow 6 \text {. Hold breath, } \rightarrow 7 \text {. Exhale through } \\
\text { the right } \rightarrow \text { Repeat the cycle }\end{array}$ & Anxiety management \\
\hline Loud breathing & ujjayi & $\begin{array}{l}\text { 1. Inhale fully through both nostrils with } \\
\text { a partially closed glottis. } \rightarrow 2 \text {. Hold the breath } \\
\text { with upper cervical spine flexion and lower } \\
\text { cervical spine extension (chin lock) and the pelvic } \\
\text { floor muscles contracted (root lock). } \rightarrow 3 \text {. Exhale } \\
\text { through the left nostril with a partially closed glotti } \\
\rightarrow 4 \text {. Hold the breath, contracting transverses abdor }\end{array}$ & $\begin{array}{l}\text { Autonomic nervous system } \\
\text { modulation. Metabolic modulation } \\
\text { tis. } \\
\text { ominus. }\end{array}$ \\
\hline
\end{tabular}

(breath control), withdrawal from sense gratification, concentration of the mind, meditation and universal consciousness (Sivananda Yoga Vedenta Centre, 1999). Yoga has been recommended in Western occupational therapy literature to promote wellbeing (Kelly \& McFarlane, 1991; Bracegirdle, 1997; Stein \& Cutler, 1998; Taylor, 2001; Kluge, 2004).

Raja yoga has been used by occupational therapists with psychiatric patients as a relaxation technique, to increase attention span, selfconfidence, coping skills, body awareness, and self-concept while providing a sense of achievement (Anderson \& Winterbone, 1979; Taylor, 2001). Eakin (1979) reported decreased reliance on medication amongst psychiatric patients practicing yoga. Occupational therapists have also used yoga for stress management, to build strength, endurance and flexibility (Giles, 1985; Kluge, 2004) and to increase service-users' awareness of their own occupational risk factors (Kluge, 2004). Occupational therapists have specifically used pranayama to facilitate physical and mental relaxation (Anderson \& Winterbone, 1979), enhance energy flow and reduce pain during performance of activities of daily living (Kluge, 2004).

While there is a growing evidence base for yoga, application of research findings is difficult, because there are several different schools of yoga and a multitude of different techniques. Testing of each individual yogic technique is arguably needed for evidence based practice. This literature review was undertaken to determine whether there is any evidence to support the use of pranayama to facilitate occupational performance. There are several pranayama techniques. Those discussed in this literature review are summarised in Table 1. The brief descriptions in the first column are not standard, but intended to ease reading for those unfamiliar with yoga terminology.

For single nostril breathing techniques, the right thumb is used to close the right nostril or the right 4 th and 5th digits are used to close the left 


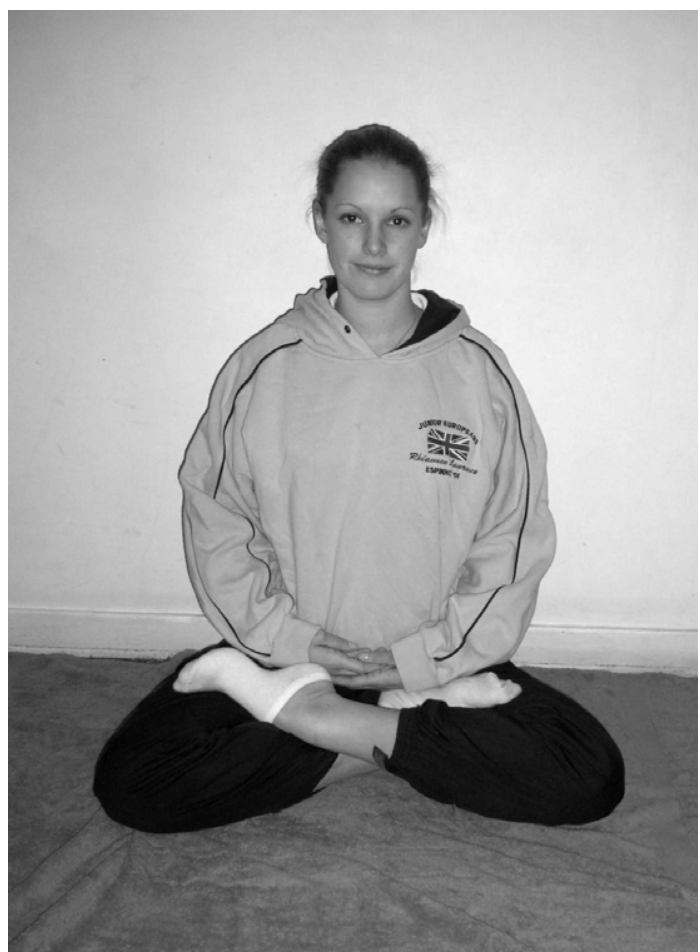

Fig. 1. The lotus position

The lotus position is a classic yoga sitting pose, used for mediation and pranayama because it is believed to enhance concentration (Sivananda Yoga Vedenta Centre, 1999). This was the position adopted by subjects in the study by Bhargava et al. (1988).

nostril. Attention is paid to the sensations of airflow in the nostrils and breath holding between inhalation and exhalation is common, though the duration of breath holding varies.

\section{Method}

A literature search using AMED, BNI, CINAHL, HMIC, Medline and Old Medline for the term 'pranayama', limited to English language human research articles produced 59 hits. Articles that did not specifically test pranayama, failed to specify the types of pranayama tested, or that could not be directly related to occupational performance were discounted. Seven articles remained. These were themed according to therapeutic effect, and analysed for validity.

\section{Literature Analysis}

\subsection{Pranayama for arousal modulation}

Arousal modulation is used by occupational therapists to facilitate occupational performance, control pain (Beresford, 1996; Hammond, 1996) and reduce health risks (King, 1996) in both mental (Duncombe, 1998) and physical settings (Cicinelli, 1996). Modalities advocated in occupational therapy literature include biofeedback (Stein \& Cutler, 1998), visualisation (Levitt, 2005) progressive muscle relaxation (Finlay, 1997; Levitt, 2005), tai chi (Stein \& Cutler, 1998), meditation (Bracegirdle, 1997; Abreu 1998; Stein \& Cutler, 1998), yoga (Anderson \& Winterbone, 1979) and breathing exercises (Levitt, 2005). As autonomic function, arousal and metabolism are inter-dependent, they are considered together in this review.

\subsubsection{Pranayama to decrease arousal}

\section{Alternate nostril breathing}

Bhargava et al. (1988) studied the effects of 4 weeks training in alternate nostril breathing and normal amplitude hyperventilation, on cardiovascular, respiratory and autonomic parameters during maximal breath holding on 10 healthy males aged 19-28. Alternate nostril breathing was practiced in the lotus position (Fig. 1) for 30 minutes per day, with 1-2 second holds after each inspiration. Once competent in alternate nostril breathing, hyperventilation was added to the regime. The subjects were not permitted to undertake any other form of exercise during the trial. Breath holding time, heart rate, electrocardiogram (ECG) and galvanic skin resistance were measured with a 4-channel polyrite (Medicare, India). Blood pressure was recorded by the auscultatory method. Subjects were tested holding their breaths maximally after normal inspiration, normal expiration, deep inspiration, full expiration, and deep inspiration after 5 maximal breaths in 15 seconds. All of the tests were conducted in controlled conditions before the subjects commenced training, and then repeated in the same conditions after 4 weeks of pranayama training. Before and after differences 
were analysed with the paired t-test.

Baseline blood pressure decreased by an average of $8.8 \mathrm{mmHg}(7 \%)$ systolic $(\mathrm{p}<0.001)$ and $4.8 \mathrm{mmHg}(7 \%)$ diastolic $(\mathrm{p}<0.05)$. Heart rate $(\mathrm{p}<0.01)$ and blood pressure $(\mathrm{p}<0.08)$ at the end point of maximal breath holding, decreased for all of the breath holding tests. All breath holding times significantly increased $(p<0.05)$ but there was no change in ECG except for heart rate, and no identifiable pattern of changes in galvanic skin resistance.

Bhargava et al. (1988) believed the observable changes were due to increased vagal tone, decreased sympathetic activity and possibly increased tolerance to raised $\mathrm{pCO}_{2}$ and low $\mathrm{pO}_{2}$. As there was no control group, the validity of this research is not assured. The results may reflect a Hawthorne effect (Polgar \& Thomas, 2000), unregulated influences or physiological adaptations to sitting in the lotus position. As Bhargava et al. (1988) combined two breathing techniques in their trial, changes cannot be scientifically attributed to either technique individually, so this research cannot support evidence based practice. Finally, the abstract of Bhargava et al. (1988) states 20 subjects were used, while the methodology states only 10 were used. This discrepancy casts doubt over the journal review process and quality of the article. Despite its methodological flaws, the work of Bhargava et al. (1988) suggests decreased sympathetic activity at baseline and in response to the stress of breath holding results from some component of alternate nostril breathing combined with hyperventilation. Research on alternate nostril breathing used alone is required to validate its use.

Pal et al. (2004) studied the effect of three months of regular alternate nostril breathing on 30 healthy male non-smoking first year undergraduate medical students (aged 17-20). The sample was randomly divided into an experimental group $(\mathrm{n}=15)$ and control group $(\mathrm{n}=15)$. Experimental subjects underwent 15 days of training in alternate nostril breathing followed by $1 / 2$ hour practice sessions every morning and evening under expert guidance for 3 months. Breathing was timed so that subjects would inhale for 6 seconds, hold their breaths for 6 seconds, exhale for 6 seconds and then hold for 6 seconds at end exhalation before inhaling again. The control group was given no instruction and was not permitted to practise pranayama. All of the subjects were on a controlled diet and were not permitted to partake in yoga or any other physical exercise for the duration of the trial.

Heart rate responses to standing, deep breathing and the valsalva manoeuvre were measured at the start and end of the experimental period to assess the effects of alternate nostril breathing on autonomic function. Heart rate was monitored with a lead II ECG Nihon Kohden multi-channel polygraph (UK). Subjects were asked to lie supine for 5 minutes and then stand. Means of recordings from 3 repetitions of experiment were taken for statistical analysis. Subjects were then asked to take a full deep inspiration followed by full expiration sitting in a chair. The biggest heart rate change reading of 3 repetitions was used for statistical analysis. Change of heart rate during forced expiration against $40 \mathrm{mmHg}$ of resistance (through a mouthpiece) was then recorded. Longest heartbeat interval after the manoeuvre was divided by the shortest heartbeat interval during the manoeuvre. Highest ratio after 3 attempts was used for statistical analysis. Data was analysed with the students' t-test and analysis of variance (ANOVA).

In the experimental group after 3 months, when compared to their pre-exercise values and the control group, basal heart rate was significantly reduced $(\mathrm{p}<0.05)(12 \%)$. Maximum heart rate in response to standing was significantly reduced $(\mathrm{p}<0.05)(7 \%$ compared to pre-exercise, $4 \%$ compared to controls) and was achieved after fewer beats $(\mathrm{p}<0.001)(20 \%$ compared to preexercise, $22 \%$ compared to controls), minimum heart rate was achieved sooner $(\mathrm{p}<0.001)(24 \%$ compared to pre-exercise, $23 \%$ compared to controls), and time taken for heart rate to stabilise was less $(\mathrm{P}<0.001)(9 \%$ compared to pre-exercise, $13 \%$ compared to controls). There were no significant valsalva ratio changes in either group.

Pal et al. (2004) concluded that slow breathing improves vagal activity and regular 
practice of slow breathing exercise for 3 months improves autonomic functions. Although Pal et al. (2004) randomly assigned subjects to their experimental and control groups, the two groups were well matched for the parameters used in their experiment. Unfortunately scientific conclusions cannot be drawn about alternate nostril breathing from this research because the effects noted may have been due to the speed of breathing. A slow breathing control group would have been more appropriate to test this type of pranayama. As significant effects were only measured after 3 months, this research does not support the use of slow alternate nostril breathing for the immediate treatment of acute anxiety. It does however support the use of this technique to treat trait anxiety or for prophylactic anxiety management in cases where anxiety impairs occupational performance.

\section{Left nostril breathing}

Telles et al. (1994) used a sample of students from the Vivekananda Kendra Yoga Research Foundation (Bangalore India) to compare the autonomic and metabolic effects of right nostril breathing $(\mathrm{n}=12)$ with left nostril breathing $(\mathrm{n}=12)$ and two alternate nostril breathing control groups $(n=12$ each). All groups were randomly selected from the sample and completed 27 cycles of their exercise 4 times per day for one month. Volar galvanic skin resistance of the ring and index fingers, heart rate and respiratory rate were measured with a 4-channel polygraph (Lafayette, USA). Oxygen consumption was measured using the closed circuit Benedict-Roth apparatus (INCO, India). All measures were taken at 4:00 am, once before training commenced and once after one month of pranayama training. Data was analysed with Wilcoxan's paired signed ranks test.

The left nostril breathing group showed a significant $(\mathrm{p}<0.05)$ increase $(145 \%)$ in volar galvanic skin resistance while no comparable change was seen in the control group. This suggests reduced sympathetic stimulation of the palm sweat glands (Telles et al., 1994). None of the other parameters significantly changed in the left nostril breathing group, but resting heart rate increased significantly in the control and right nostril breathing groups. Telles et al. (1994) concluded that left nostril breathing modulates some sympathetic outflows but not others.

Telles et al. (1994) could have increased the power of their statistical testing by allocating 16 subjects to each of two experimental groups and one control, instead of 12 to each group with 2 separate controls. They looked for statistically significant differences within each group, but did not analyse the significance of differences between the groups. The groups were subjected to a controlled lifestyle and diet for the duration of the trial, but were randomly selected and not deliberately matched by physiological variables. Alternate nostril breathing is not a suitable control, because it involves repeated periods of left nostril breathing. Normal breathing may have been more suitable. All of the subjects underwent general yoga training during the trial. This may have complicated the physiological changes identified in the groups. Due to these factors, while this research suggests left nostril breathing may reduce arousal, the evidence presented is weak and inconclusive. Even if the difference in galvanic skin resistance was due to the effect of left nostril breathing on sympathetic outflow, that difference may not be clinically significant for occupational therapy.

\section{Loud yogic breathing with long breath holding}

Telles \& Desiraju (1991) studied breath holding during loud breathing (ujjayi) without chin lock, in 5 healthy males. Subjects were selected because they normally practised this breathing technique. The time ratio of inspiration:holding:expiration was 1:4:2. Tidal volume, and respiratory rate were measured with a spirometer. Oxygen consumption was measured with Benedict-Roth apparatus. Telles \& Desiraju (1991) utilised a same-subject controlled repeated measurements design. Readings of 4 minutes duration were taken before, during and after each pranayama practice. The duration of each pranayama practice may have been 4 minutes, but this was not clearly described by the authors. Test sessions were repeated 10-15 times each. The averages of the measurements for each subject 
from all of the test sessions were used for data analysis.

DuBois formula was applied to estimate metabolic rate and data was analysed with the matched t-test and 2-way ANOVA. There was a mean $19 \%$ decrease in oxygen consumption during loud yogic breathing (t-test $\mathrm{p}<0.05$ ANOVA $p<0.03$; F 5.8 , df 2,8) but parameters returned to baseline in the post pranayama test period. Telles \& Desiraju (1991) concluded that loud yogic breathing with long breath holding reduces metabolic rate by $20 \%$. This conclusion was based on the fact that parameters returned to normal immediately after pranayama, indicating that no oxygen debt occurred despite decreased oxygen consumption.

Telles \& Desiraju (1991) used parametric tests that are arguably too sensitive for their sample size of 5. There is little evidence to support use of the DuBois formula to estimate metabolic rate (Gibson \& Numa, 2003) so the extrapolations made may not be accurate. The reason for variation between subjects of the numbers of repeat test sessions is not clear, and this could have been influenced by experimenter bias. Telles \& Desiraju (1991) considered the before-pranayama measurements of each test session to be a control. This did not eliminate the possibility of order effects. Neither does it validate the use of yogic loud breathing instead of breath holding alone. Finally, because anxious and hyperactive people are the main target groups for arousal reducing techniques, loud yogic breathing with long breath holding requires expert instruction, and the effects of pranayama in this study did not last beyond the duration of its practice, Telles \& Desiraju (1991) proved no applicability of this technique to occupational therapy.

\subsubsection{Pranayama to increase arousal}

\section{Loud yogic breathing with short breath holding}

Telles \& Desiraju (1991) studied short breath holding during loud breathing (ujjayi) without chin lock, in 5 healthy males who usually used this type of pranayama. Telles \& Desiraju (1991) used the same methodology as described for their testing of loud yogic breathing with long breath holding (described above), with two exceptions. The time ratio of inspiration:holding:expiration was 1:1 or less:1, and test sessions were repeated only 7-14 times each. Oxygen consumption increased significantly (t-test $\mathrm{p}<0.025$, ANOVA $\mathrm{p}<0.01$; F $8.7 \mathrm{df} 2,8$ ) by an average of $52 \%$ during pranayama but returned to baseline in the post pranayama test period. Telles \& Desiraju (1991) concluded that short breath holding loud yogic breathing increases metabolic rate by over $70 \%$.

The methodological weaknesses of Telles \& Desiraju (1991) are summarised above. It is possible that the breath-holding component of this breathing exercise does not contribute towards its positive effect on metabolic rate. If Telles \& Desiraju's (1991) findings are accurate loud yogic breathing could possibly be used to treat obesity or hypothyroidism. Confirmation is required by independent research with a larger sample. As the effect of loud yogic breathing on metabolism did not last beyond the duration of the exercise practice, it is unlikely this technique could enhance short-term occupational performance. Current English language research evidence does not therefore justify its use as an occupational therapy tool.

\section{Right nostril breathing}

Telles et al. (1994) (methodology described on page 12) found that resting oxygen consumption increased by $37 \%(p<0.05)$ after a month of four-times-daily practise of right nostril breathing, but did not change significantly with left or alternate nostril breathing. Heart rate increased significantly $(\mathrm{p}<0.001)$ with right $(10 \%)$ and alternate $(7 \%)$ nostril breathing, but not with left nostril breathing. Telles et al. (1994) concluded that right nostril breathing increases metabolism. As heart rate is a function of arousal, it is possible that right nostril breathing affected waking arousal levels as well as metabolism. Telles et al. (1994) failed to specify the durations of their oxygen consumption measurements, so it is difficult to gauge the reliability of their findings. It is possible that yoga training which all of the subjects were exposed to was responsible for the increase in metabolism and this adaptation was 
inhibited in some way by left nostril breathing.

Telles et al. (1996) tested right nostril breathing on 8 female and 4 male volunteer yoga students $(n=12)$ free of major illnesses with a randomised crossed-over same subject controlled trial. Normal breathing was the control. Experimental and control assessments were taken on two separate consecutive days. Oxygen consumption over 5 minutes was measured using the closed circuit Benedict-Roth apparatus (INCO, India). Heart rate, volar galvanic skin resistance of the ring and index finger tips, and respiratory rate were measured over 10 minutes using a 10 channel polygraph (Medicare India). Blood pressure was measured with a stethoscope and mercury sphygmomanometer. Digit pulse volume was measured with a photoplethysmograph on the volar surface of the distal phalanx of the left thumb. Baseline measures were taken as soon as the subjects woke. The experiment or control was then practised for 45 minutes and then the measures were repeated. Data was analysed with the 2-factor ANOVA, multiple comparison Tukey test and t-test for paired data. A $17 \%$ average increase in oxygen consumption $(p<0.05), 9.4$ $\mathrm{mmHg}$ average increase in systolic blood pressure $(\mathrm{p}<0.05)$ and $45.7 \%$ decrease in digit pulse volume $(p<0.05)$ were apparent in the experimental trials, but there were no significant changes in the control. These haemodynamic changes are consistent with increased arousal. Telles et al. (1996) therefore concluded that right nostril breathing stimulates increased metabolism, and may increase cardiac sympathetic tone or reduce vagal tone. The equipment used by Telles et al. (1996) is respected as standard for the parameters measured. If the subjects were normally distributed for the parameters tested, this research trial was well constructed and supports the use of right nostril breathing to arouse and increase the metabolic rate of healthy individuals. Trials of right nostril breathing on patient groups with poor arousal or metabolic deficiencies are required to fully validate its clinical use.

\subsection{Pranayama for Exercise tolerance}

Exercise tolerance and fatigue can be major limiting factors of occupational performance.
Traditionally, occupational therapists manage fatigue with practical adaptations and energy conservation (Mailoo \& Williams, 2004). Kluge (2004) however recommended yoga to increase energy levels and endurance.

\section{Full yogic breathing combined with alternate nostril breathing}

Raju et al. (1986) tested the effect of 20 days of pranayama training on exercise tolerance in 12 healthy volunteers ( 6 male, 6 female) of comparable age undergoing a yoga training certificate course. All of the subjects were from sedentary backgrounds.

Submaximal exercise testing was conducted using Balke's protocol, which was widely considered the most appropriate method (Roca et al. 1997). Each subject was tested on a motorised treadmill (Venky, India) on an empty stomach in an air-conditioned room. Heart rate and ECG were measured with a cardiac monitor (Olli-Finland). Blood pressure was measured with a sphygmomanometer. Minute ventilation and fractional oxygen in expired air were measured by the Morgan Transfer Test (P.K. Morgan Ltd, England). Fractional expired $\mathrm{CO}_{2}$ was measured with Haldane's apparatus. $\mathrm{pO}_{2}$ and $\mathrm{SaO}_{2}$ from capillary blood were measured with an AVLMicro Blood Gas Analyser (Switzerland). The above parameters were initially recorded at rest and then during every 4 th minute of sub-maximal exercise. Urine samples were taken before and after exercise to measure urinary lactate, and blood taken from the antecubital vein before and immediately after exercise was used to measure blood lactate and pyruvate. Lactate was estimated with the Barker \& Summerson method (Barker, 1983). Pyruvate was estimated using the Friedemann Haugen method, which was widely recognised as simple and accurate (Wolcott, 1985). Rate of oxygen consumption $\left(\mathrm{VO}_{2}\right)$ was estimated from the minute ventilation, fraction of expired $\mathrm{CO}_{2}$ and fraction of $\mathrm{O}_{2}$.

Following initial exercise testing, subjects practised full yogic breathing, full yogic breathing with breath holding, alternate nostril breathing and alternate nostril breathing with breath holding sequentially for 10 minutes each, followed by 20 
minutes of supine relaxed lying, daily for 20 days. After 20 days exercise testing was repeated. Data was analysed with the student's paired t-test. In the male subjects immediate post-exercise $\mathrm{pO}_{2}$ was significantly $(\mathrm{p}<0.05)$ increased $(9 \%)$ after pranayama training compared to pre-training, and there were significant $(\mathrm{p}<0.05)$ reductions $(41 \%)$ in minute ventilation and $\mathrm{VO}_{2}$. Urinary lactate significantly increased with initial exercise testing but not with exercise testing post training. In females, immediate post-exercise $\mathrm{pO}_{2}$ was significantly $(\mathrm{p}<0.05)$ increased $(29 \%)$ after pranayama training compared to pre-training.

The Barker \& Summerson method was once the most respected way of estimating lactate concentrations, but it is easily contaminated due to its high sensitivity (Barker, 1983). It has therefore been superseded by spectrophotometric analysis with lactic dehydrogenase (Barker, 1983). The Raju et al. (1986) methodology would have been more reliable if they used up-to-date technology. It is also unclear why they considered data for males and females separately. This may simply be because some differences were not statistically significant when the sample was considered as a whole. The individual sex sample sizes of 6 may be too small to ensure external validity. As there was no control group, the changes seen may have been due to unrecorded influences. The periods of relaxed supine lying may also have facilitated adaptation, but this is unlikely to have been significant, considering that many people adopt supine lying during sleep. The only relevant conclusion that can be drawn from this research is that that training in a combination of full yogic and alternate nostril breathing with breath holding may increase post exercise $\mathrm{pO}_{2}$, thus facilitating recovery from exercise. Repetition of this research design with a control group, separate experimental groups for each technique, modern technology and a larger sample size might provide more solid evidence for the use of either alternate nostril breathing, full yogic breathing, or both to increase exercise tolerance.

\subsection{Pranayama for strength}

Raghuraj et al. (1997) tested the effects of left, right and alternate nostril breathing on grip strength in right-handed children aged 11 to 18 . A sample of 130 was randomly divided into five groups. These were right nostril breathing $(n=30)$, left nostril breathing $(n=30)$, alternate nostril breathing $(n=30)$, breath awareness $(n=30)$ and hand positioning (as normally used to close nostrils $n=10)$. All breathing exercises were practiced for 27 repetitions 4 times a day. Left and right hand grip strength (best of three attempts) measured with a grip dynamometer (Anand Agencies, India) at the beginning and end of a 10 day yoga camp.

Right grip strength increased significantly with alternate nostril breathing $(\mathrm{t}=3.19 \mathrm{p}<0.005)$, right nostril breathing $(\mathrm{t}=2.69 \mathrm{p}<0.05)$ and left nostril breathing $(\mathrm{t}=2.95 \mathrm{p}<0.01)$. Left grip strength also increased significantly with alternate nostril breathing $(\mathrm{t}=2.13 \mathrm{p}<0.05)$, right nostril breathing $(\mathrm{t}=3.45 \mathrm{p}<0.002)$ and left nostril breathing $(\mathrm{t}=2.31 \mathrm{p}<0.05)$. The breath awareness and hand posture groups showed no significant increases.

Raghuraj et al. (1997) concluded right, left and alternate nostril breathing can increase hand grip strength, but proposed no physiological mechanisms behind their findings. The long term effects of single or alternate nostril breathing on grip strength were not determined by this study. The groups were not matched, and as the results are not explainable in physiological or medical terms independent research is required to confirm or reject the validity of the results.

\section{Cautions}

Complete review of all pranayama related literature is beyond the scope of this paper. Pranayama practice based on the information provided in this paper alone is not advised and may not be safe. Hyperventilation can cause fainting and contributes to bowel disorders (Limb, 2005). No adverse effects from any of the other techniques mentioned in this paper were highlighted in the literature reviewed. Another pranayama technique has however been anecdotally associated with pneumothorax (Johnson et al., 2004). Techniques have been described in this document to aid estimation of 
their physiological effects only. Therapists and members of the public wishing to learn pranayama should seek authoritative instruction.

\section{Summary}

Much of the published research on pranayama, does not support evidence based practice due to poor specificity. Evidence from one research publication weakly suggests that loud yogic breathing without breath holding may increase metabolism during periods of practice. No evidence to the contrary was uncovered. There is also weak evidence from one research paper that alternate nostril breathing practiced 4 times daily in conjunction with full yogic breathing may increase exercise tolerance. Reasonable evidence from one publication suggests that three months practice of slow alternate nostril breathing increases vagal tone and improves aspects of autonomic nervous system function. It is not clear which properties of slow alternate nostril breathing are responsible for these effects, but this technique may be a useful tool for occupational therapists in the treatment of trait anxiety. There is strong evidence from one publication that right nostril breathing increases metabolic rate during the period of practice, and weak evidence from another paper that this effect may be prolonged. Other research not analysed in this review suggests health benefits from pranayama that are not directly related to occupation.

\section{Conclusions}

Occupational therapists who integrate yoga into their practice and use pranayama, should consider choice of technique based on the pathology and physiological needs of each individual service-user, and the evidence of therapeutic effect for each technique. Slow alternate nostril breathing should be considered when anxiety impairs occupational performance, and right nostril breathing should be considered for obesity, lethargy, and symptoms of hypothyroidism or similar metabolic disorders if these inhibit function. Further research is required for evidence-based application of other pranayama techniques.

\section{Acknowledgements}

The author would like to thank Rhiannon Lawrence (model).

\section{References}

Abreu, B.C. (1998). The quadraphonic approach: Holistic rehabilitation for brain injury. In: Katz, N. (ed.), Cognition and occupation in rehabilitation. Cognitive models for intervention in occupational therapy. pp. 51-97. Bethesda: American Occupational Therapy Association.

Anderson, F., Winterbone, A. (1979). Yoga in a short stay Psychiatric Unit. Br. J. Occup. Ther., 42(8), 191-193.

Barker, S. B. \& Summerson, W. H. (1983). The colorimetric determination of lactic acid in biological material. J. Biol. Chem. 138: 535-554.

Beresford, S. (1996). Cancer. In: Turner, A., Foster, M., \& Johnson, S.E. (eds.) Occupational therapy and physical dysfunction. Principles, skills and practice. 4th ed., pp. 851-870. New York: Churchill Livingstone.

Bhargava, R., Gogate, M.G., \& Mascarenhas, J.F. (1988). Autonomic responses to breath holding and its variations following pranayama. Indian Journal of Physiology \& Pharmacology, 32(4), 257-264.

Bracegirdle, H. (1997). Developing physical fitness to promote mental health. In: Creek, J. (ed.) Occupational therapy and mental health. 2nd ed., pp. 195-211. New York: Churchill Livingstone.

Cicinelli, L. (1996). Back pain. In: Turner, A., Foster, M., Johnson, S.E. (eds.), Occupational therapy and physical dysfunction. Principles, skills and practice. 4th ed., pp. 667-690. New York: Churchill Livingstone.

Duncombe, L. (1998). The cognitive-behavioural model in mental health. In: Katz, N. (ed.), Cognition and occupation in rehabilitation. Cognitive models for intervention in occupational therapy. pp. 165-191. Bethesda: American Occupational Therapy Association.

Eakin, P. (1979). Yoga (letter). Br. J. Occup. Ther., 42(11), 295-296.

Finlay, L. (1997). The practice of psychosocial occupational therapy. 2nd ed., Cheltenham: Stanley Thornes. 
Gibson, S., Numa, A. (2003). The importance of metabolic rate and the folly of body surface area calculations. Anaesthesia, 58, 50-83.

Giles, G.M. (1985). Anorexia nervosa and bulimia: An activity-oriented approach. Am. J. Occup. Ther., 39(8), 510-517.

Hammond, A. (1996). Rheumatoid arthritis. In: Turner, A., Foster, M., \& Johnson, S.E. (eds.), Occupational therapy and physical dysfunction. Principles, skills and practice. 4th edition, pp. 747-765. New York: Churchill Livingstone.

Johnson, D.B., Tierney, M.J., \& Sadighi, P.J. (2004). Kapalabhati pranayama: Breath of fire or cause of pneumothorax? A case report. Chest, 125(5), 1951-1952.

Kelly, G. \& McFarlane, H. (1991). Zen in the art of occupational therapy, part two. Br. J. Occup. Ther. 54(4), 130-134.

Khalsa, G.K. (2005). Kundalini Yoga. Available from URL: http://www.kundaliniyoga.org/ accessed 14:39 29/1/2006.

King, J.C. (1996). Acute cardiovascular disorder and disease. In: Turner, A., Foster, M., \& Johnson, S.E. (eds.) Occupational therapy and physical dysfunction. Principles, skills and practice. 4th edition, pp. 779-796. New York: Churchill Livingstone.

Kluge, J. (2004). Yoga therapy. An integrative approach. OT Practice, 9(17), 22-24.

Levitt, V.B. (2005). Anxiety disorders. In: Cara, E., \& MacRae, A. (eds). Psychosocial occupational therapy. A clinical practice. 2nd ed., pp. 193-234. New York: Thomson Delmar Learning.

Limb, M. (2005). Gut response to better breathing. Frontline, 11(19), 16.

Mailoo, V.J. (2005). Yoga: An ancient occupational therapy? Br. J. Occup. Ther., 68(12), 574-577.

Mailoo, V.J., Williams, C.J. (2004). Psychoneuroimmunology: A theoretical basis for occupational therapy in oncology? Int. J. Ther. Rehabil., 11(1), 7-12.

Pal, G.K., Velkumary, S., \& Madanmohan (2004). Effect of short term practice of breathing exercises on autonomic functions in normal human volunteers. Indian Journal of Medical Research, 120(2), 115-121.

Polgar, S., \& Thomas, S.A. (2000). Introduction to research in the health sciences. 4th edition. Edinburgh: Elsevier Churchill Livingstone.

Raghuraj, P., Nagarathna, R., Nagendra, H.R., \& Telles, S. (1997). Pranayama increases grip strength without lateralized effects. Indian
Journal of Physiology \& Pharmacology, 41(2): 129-133.

Raju, P.S., Kumar, K.A., Reddy, S.S., Madhavi, S., Gnanakumari, K., Bhaskaracharyulu, C., Reddy, M.V., Annapurna, N., Reddy, M.E., Girijakumari, D., Sahay, B.K., \& Murthy, K.J.R. (1986). Effect of yoga on exercise tolerance in normal healthy volunteers. Indian Journal of Physiology and Pharmacology, 30(2), 121-132.

Roca, J., Whipp, B.J., Agusti, A.G.N., Anderson, S.D., Casaburi, R., Cotes, J.E., Donner, C.F., Estenne, M., Folgering, H., Higenbottam, T.W., Killian, K.J., Palange, P., Patessio, A., Prefaut, C., Sergysels, R., Wagner, P.D., \& Weisman, I. (1997). Clinical exercise testing with reference to lung diseases: indications, standardization and interpretation strategies. Eur. Respir. J. 10, 26622689.

Sivananda Yoga Vedanta Centre (1999). Yoga mind \& body. London: Dorling Kindersley.

Stein, F., \& Cutler, S.K. (1998). Psychosocial occupational therapy. San Diego: Singular Publishing Group.

Swami Prabhupada, A.C.B. (1982). Srimad Bhagavatam of Krsna-Dvaipayana Vyasa. One volume edition. New York: Bhaktivedanta Book Trust.

Taylor, S. (2001). Introducing a yoga group in an acute inpatient psychiatric facility. OT Practice, 6(6), 22-23.

Telles, S., \& Desiraju, T. (1991). Oxygen consumption during pranayamic type of very slow-rate breathing. Indian Journal of Medical Research, 94, 357-363.

Telles, S., Nagarathna, R., \& Nagendra, H.R. (1994). Breathing through a particular nostril can alter metabolism and autonomic activities. Indian Journal of Physiology and Pharmacology, 38(2), 133-137.

Telles, S., Nagarathna, R., \& Nagendra, H.R. (1996). Physiological measures of right nostril breathing. Journal of Alternative and Complementary Medicine, 2(4), 479-484.

Walker, M.F., Drummond, A.E., Gatt, J., \& Sackley, C.M., (2000). Occupational therapy for stroke patients: A survey of current practice. $B r . J$. Occup. Ther., 63(8), 367-372.

Wolcott, G.H., Freideman, T.E. \& Haugen, G.E. (1985) Pyruvic acid II. The determination of keto acids in blood and urine. J. Biol. Chem. 147: 415442. 